doi:10.12662/2359-618xregea.v9i1.p136-153.2020

ARTIGOS

\title{
OS JOVENS MILITARES SÃO ALFABETIZADOS FINANCEIRAMENTE? ESTUDO EM UMA ORGANIZAÇÃO DA FRONTEIRA GAÚCHA
}

\author{
ARE YOUNG MILITARY MEN FINANCIALLY \\ LITERATE? STUDY IN A GAUCHO FRONTIER \\ ORGANIZATION
}

\section{RESUMO}

Levando em consideração a existência de uma lacuna educacio-

André Luis Baumhardt Zuliani zuliani.int@gmail.com Pós-Graduando em Administração Pública pela Universidade Estácio de Sá.

Silvia Amélia Mendonça Flores silviaflores@unipampa.edu.br Professora Assistente na Universidade Federal do Pampa. Doutoranda em Administração pela Universidade Federal de Santa Maria. Santa Maria - RS - BR.

Mikaela Daiane Prestes Floriano mikaelapfloriano@gmail.com Mestranda em Administração pela Universidade Federal do Pampa. Bagé - RS - BR.

Ana Carolina Josende anacarolina_cj@yahoo.com.br Professora na Universidade Franciscana. Mestre em Engenharia da Produção pela Universidade Federal de Santa Maria. Santa Maria - RS - BR.

Thadeu José Francisco Ramos thadeuramos@unipampa.edu.br Professor Adjunto na Universidade Federal do Pampa. Mestre em Administração pela Universidade Federal do Rio Grande do Sul. Porto Alegre$R S-B R$. nal, o presente artigo teve como objetivo estimar o nível de alfabetização financeira dos militares de uma Organização Militar da fronteira gaúcha. Para tanto, realizou-se um estudo descritivo, de abordagem quantitativa, usando o método do tipo Survey. Os dados desta pesquisa foram coletados com um instrumento e uma metodologia de mensuração já validada anteriormente. Os resultados encontrados sugerem que a maior parte dos respondentes apresenta um baixo nível de alfabetização financeira. E, ainda, que a dimensão das atitudes pouco influi na formação dos níveis de alfabetização financeira. Foi possível, também, verificar a relação direta entre conhecimentos financeiros e comportamentos financeiros. Os achados reforçam a necessidade de implementação de programas rígidos de alfabetização financeira à população em geral, de forma a ampliar o alcance da Estratégia Nacional de Educação Financeira (ENEF).

Palavras-chave: Alfabetização financeira. Educação financeira. Finanças pessoais.

\section{ABSTRACT}

Taking into consideration the existence of an educational gap, this article aimed to estimate the level of financial literacy of the military personnel of a Military Organization of the state of Rio Grande do Sul. For that, a descriptive study with a quantitative approach was performed using the Survey-type method. The data of this research were collected with a measurement instrument and a methodology already validated previously. The results found suggest that most respondents have a low level of financial literacy. It was concluded that the dimension of attitudes has little influence on the formation of financial literacy levels. It was possible to 
verify the direct relationship between financial knowledge and financial behavior. The findings reinforce the need to implement strict financial literacy programs for the general population in order to broaden the reach of the National Strategy for Final Education (NSFE).

Keywords: Financial literacy. Financial education. Personal finances.

\section{INTRODUÇÃO}

Em períodos anteriores, a condução da política econômica brasileira foi caracterizada, entre outros fatores, pelo impulso ao consumo doméstico. Esse fato, mais marcante entre os anos de 2006 e 2010, teve como uma de suas características a transferência de renda e o estímulo ao consumo das famílias (GIAMBIAGI; VILLELA, 2011). Com isso, o acesso aos produtos e aos serviços do sistema financeiro se estendeu a uma parcela da população que, até então, encontrava-se excluída desse sistema (BACEN, 2013); contudo, os bons momentos vividos na economia brasileira na última década trouxeram um lado perverso: o aumento do endividamento das famílias (FERNANDES; CANDIDO, 2014).

Esse contexto econômico culminou no desequilíbrio financeiro das famílias brasileiras, fazendo com que a temática de educação financeira recebesse maior atenção por parte das instituições públicas e privadas. Essa preocupação com a educação financeira justifica-se por ela fornecer as bases de conhecimento necessárias para que os indivíduos administrem seus rendimentos com eficiência, planejando e controlando seus gastos (SANTOS, 2014; LUSARDI, 2015).

No entanto, a educação financeira é entendida como uma medida preventiva (ANDERLONI; VANDONE, 2010), sendo o conhecimento financeiro o principal foco (POTRICH; VIEIRA; KIRCH, 2014). Com o avanço das pesquisas, em um conceito mais amplo e completo, surgiu a alfabetização financeira. Ela é conceituada como uma combinação de elementos (consciência, conhecimento, habilidade, atitude e comportamento) necessários para os indivíduos tomarem decisões financeiras adequadas com o intuito de alcançar o bem-estar financeiro (ATKINSON; MESSY, 2012; OECD, 2012).

Com base no exposto, nota-se a importância da alfabetização financeira, tendo em vista a existência de uma lacuna educacional, com implicações que comprometem a segurança financeira dos indivíduos, inclusive, daqueles mais jovens (LUSARDI, 2015). Especificamente, tendo por base o público-alvo desse estudo, evidencia-se que o serviço militar obrigatório pode ser uma alternativa de entrada no mercado de trabalho e inclusão financeira. Mesmo se tratando de uma obrigação constitucional e não um trabalho assalariado propriamente dito, todos os anos, milhares de brasileiros cumprem esse dever cívico, por vezes, buscando, nas Forças Armadas, sua primeira fonte de renda. Para as classes menos favorecidas, o serviço militar mostra-se como uma oportunidade para o aprimoramento técnico-profissional, que, posteriormente, servirá como meio de ingresso no mercado de trabalho (LEAL, 2008).

Ao considerar que o Exército Brasileiro possui o maior efetivo entre as três Forças, e que comportamentos financeiros adequados trazem benefícios para o indivíduo e para sociedade, parece pertinente identificar o nível de alfabetização financeira de jovens ingressantes no mercado de consumo. Dessa forma, este artigo tem a finalidade de responder ao seguinte questionamento: Qual o grau de alfabetização financeira dos militares de uma Organização Militar (OM) de fronteira no Sul do Brasil?

Desse modo, o objetivo geral busca estimar o nível de alfabetização financeira dos militares de uma Organização Militar de fronteira no Sul do Brasil. E, especificamente, pretende-se i) identificar o grau de conhecimento financeiro dos militares; ii) avaliar os comportamentos financeiros desses militares; iii) analisar suas atitudes financeiras e iv) comparar esses atributos por nível hierárquico e por variáveis 
socioeconômicas. A contribuição teórica deste estudo consiste na caracterização do perfil financeiro de adultos jovens, que cumprem o serviço militar obrigatório, tendo, como base, uma metodologia validada previamente (POTRICH; VIEIRA; KIRCH, 2014).

Como contribuição empírica, tem-se a investigação de um corte sociodemográfico específico, representado por um público jovem e com renda própria. Assim, a pesquisa diferencia-se das demais, que, comumente, analisam a alfabetização financeira de estudantes de nível médio, superior ou de pós-graduação.

Este artigo foi organizado em quatro partes além dessa introdução. A segunda refere-se à revisão teórica. A metodologia está contemplada na terceira parte do artigo, seguida da análise e discussão dos resultados. Em seguida, apresentam-se as considerações finais.

\section{REVISÃO DA LITERATURA}

Neste capítulo, são apresentadas as teorias que irão auxiliar na investigação sobre a alfabetização financeira, sendo evidenciadas as principais definições e características do referido fenômeno.

\subsection{EDUCAÇÃO E ALFABETIZA- ÇÃO FINANCEIRA}

Segundo a OECD (2005), educação financeira pode ser definida como o processo pelo qual os indivíduos incrementam sua compreensão sobre produtos e conceitos financeiros por meio de informação, instrução e aconselhamento. Além disso, desenvolvem habilidades e ganham confiança para tomar decisões mais embasadas, com ciência dos riscos e das oportunidades envolvidas, entre outras ações que maximizem o seu bem-estar financeiro. $\mathrm{O}$ propósito da educação financeira é formar cidadãos capazes de planejar melhor suas ações e honrar seus compromissos financeiros (OECD, 2005). Logo, mostra-se crescente o número de governantes que desenvolve estratégias de âmbito nacional para que fomente a capacida- de financeira de seus habitantes (KEMPSON, 2009).

No Brasil, a Estratégia Nacional de Educação Financeira (ENEF) foi implantada no ano de 2010, buscando "promover a educação financeira e previdenciária e contribuir para o fortalecimento da cidadania, a eficiência e solidez do sistema financeiro nacional e a tomada de decisões conscientes por parte dos consumidores." (BRASIL, 2010, online). Trata-se de uma estratégia que compreende os esforços de entidades públicas e privadas para difundir conhecimentos financeiros entre diversas camadas da população.

Contudo, apesar da existência de uma política pública de fomento à educação financeira, persiste, no nosso meio, um hiato de conhecimentos financeiros. Historicamente, o descontrole inflacionário e as grandes variações monetárias e cambiais foram características marcantes da economia brasileira. Essa conjuntura dificulta o planejamento financeiro das famílias e as decisões tomadas tinham o curto prazo como prioridade, sendo essa uma hipótese para o atraso da preocupação com a educação financeira no país.

Ao encontro dessa posição, Fernandes e Candido (2014) e Dietrich e Braído (2016) afirmam que o despreparo das gerações mais novas em tratar com as finanças pessoais faz que essa camada da população apresente proporção maior de endividados em comparação com seus ascendentes. Em complemento, Kim, Anderson e Seay (2017) indicaram que representantes da geração millennials apresentam baixo nível de conhecimentos financeiros, demonstrando excesso de confiança em suas decisões.

Sabendo da importância dessa temática, surge uma nova contextualização, guiada pelo conceito de alfabetização financeira. A OECD (2013) dividiu a alfabetização financeira em três dimensões, sendo elas, o conhecimento financeiro, o comportamento financeiro e a atitude financeira.

Delavande, Rohwedder e Willis (2008) trataram o conhecimento financeiro como uma espécie de capital humano. Adquiri-lo pode ser 
considerado um investimento, pois possibilita que as famílias aprimorem certas habilidades ao passo que obtêm taxa de retorno superior em seus ativos, mantendo o risco constante. O comportamento é um componente essencial da alfabetização financeira, sendo considerado o mais importante. Refere-se aos hábitos que conduzem a resultados positivos ou negativos na gestão financeira pessoal (ATKINSON; MESSY, 2012). Por fim, as atitudes financeiras dizem respeito às preferências individuais, no que tange às prioridades de emprego de recur- sos - se possuem foco imediatista ou se consideram o longo prazo (OECD, 2013).

Os debates sobre a alfabetização financeira têm crescido no meio acadêmico, empresarial e governamental e é crescente o número de estudos que se propuseram a mensurar o nível de alfabetização financeira, permitindo que as iniciativas de fomento sejam alinhadas às necessidades populacionais. O quadro 1 apresenta alguns desses estudos, dividindo-os entre os realizados no Brasil e os realizados em outros países:

Quadro 1- Estudos relacionados à educação e à alfabetização financeira

\begin{tabular}{|c|c|c|}
\hline \multicolumn{3}{|c|}{ Estudos realizados no Brasil } \\
\hline Objetivos & Resultados & Autores \\
\hline $\begin{array}{l}\text { Mapear a Educação Financeira de } \\
\text { servidores públicos de Caraguatatuba } \\
\text { de acordo com seu comportamento } \\
\text { financeiro e sua propensão ao } \\
\text { endividamento e ao materialismo. }\end{array}$ & $\begin{array}{l}\text { Comprovou-se a relação inversamente proporcional } \\
\text { entre a educação financeira e o endividamento e, } \\
\text { também, a relação entre atitude de risco e autocontrole } \\
\text { com o materialismo e a relação entre o materialismo } \\
\text { e o endividamento. }\end{array}$ & $\begin{array}{l}\text { Ávila e } \\
\text { F erreir a } \\
(2019)\end{array}$ \\
\hline $\begin{array}{l}\text { Analisar a importância da educação } \\
\text { financeira para os alunos da Escola } \\
\text { Estadual de Ensino Fundamental e } \\
\text { Médio Afonso Machado Coelho. }\end{array}$ & $\begin{array}{l}\text { Apesar de a educação financeira ser um tema } \\
\text { relevante para o aluno de ensino fundamental e } \\
\text { médio, é um assunto pouco abordado em sala de } \\
\text { aula. A educação financeira se torna uma ferramenta } \\
\text { de auxílio para os alunos, ajudando-os na tomada } \\
\text { de decisões, na administração de seus recursos e na } \\
\text { manutenção de seu bem-estar financeiro. }\end{array}$ & $\begin{array}{l}\text { Carvalho } \\
\text { e Scholz } \\
(2018)\end{array}$ \\
\hline $\begin{array}{l}\text { Avaliar o efeito do conhecimento } \\
\text { financeiro e da orientação para } \\
\text { o futuro no nível de segurança } \\
\text { financeira pessoal e identificar se } \\
\text { o conhecimento financeiro é uma } \\
\text { variável mediadora da relação } \\
\text { entre orientação para o futuro e a } \\
\text { segurança financeira pessoal. }\end{array}$ & $\begin{array}{l}\text { Identificada relação proporcional direta entre } \\
\text { a orientação para o futuro, o interesse pelo } \\
\text { conhecimento financeiro e a segurança financeira } \\
\text { dos indivíduos. Os indivíduos detentores de maiores } \\
\text { níveis de conhecimentos financeiros apresentam } \\
\text { maior nível de segurança financeira. }\end{array}$ & $\begin{array}{l}\text { Gonçalves } \\
\text { e Ponchio } \\
(2018)\end{array}$ \\
\hline $\begin{array}{l}\text { Analisar o nível de alfabetização } \\
\text { financeira de trabalhadores que } \\
\text { passaram pelo programa de } \\
\text { educação financeira da empresa em } \\
\text { que trabalham. }\end{array}$ & $\begin{array}{l}\text { A maior parte dos pesquisados apresentou } \\
\text { nível adequado de alfabetização financeira, } \\
\text { sendo os resultados relacionados a variáveis } \\
\text { sociodemográficas. Os empregados, com maior } \\
\text { participação nos programas de educação financeira, } \\
\text { tiveram desempenho superior. Há relação positiva } \\
\text { entre atitude, comportamento e conhecimento. }\end{array}$ & $\begin{array}{l}\text { Oliveira } \\
\text { e Santana } \\
(2019)\end{array}$ \\
\hline $\begin{array}{l}\text { Relacionar a educação financeira } \\
\text { com os hábitos de consumo, } \\
\text { investimento e a percepção de risco } \\
\text { de servidores públicos. }\end{array}$ & $\begin{array}{l}\text { Os investigados, que apresentam baixo nível de } \\
\text { educação financeira, são menos propensos ao } \\
\text { risco e apresentam um perfil mais conservador em } \\
\text { relação às decisões financeiras. A dificuldade em } \\
\text { gerir as finanças pessoais e o fácil acesso ao crédito } \\
\text { comprometem as decisões financeiras. }\end{array}$ & $\begin{array}{l}\text { Silva et al. } \\
\text { (2017) }\end{array}$ \\
\hline
\end{tabular}




\begin{tabular}{|c|c|c|}
\hline $\begin{array}{l}\text { Identificar se os alunos de } \\
\text { especialização de uma Instituição } \\
\text { de Ensino Superior realizam um } \\
\text { planejamento financeiro para a } \\
\text { aposentadoria. }\end{array}$ & $\begin{array}{l}\text { Os investigados apresentam um baixo nível de } \\
\text { conhecimento sobre finanças pessoais e a maior } \\
\text { parte desses não realiza planejamento financeiro para } \\
\text { aposentadoria, alegando falta de recursos ou serem } \\
\text { muito jovens para iniciar esse planejamento. }\end{array}$ & $\begin{array}{l}\text { Dietrich } \\
\text { e Braido } \\
\text { (2016) }\end{array}$ \\
\hline $\begin{array}{l}\text { Identificar os motivos que levam } \\
\text { alunos de pós-graduação a contrair } \\
\text { dívidas, apurando se o período da } \\
\text { infância e da adolescência é mais } \\
\text { efetivo para obter boa educação } \\
\text { financeira. }\end{array}$ & $\begin{array}{l}\text { Os pesquisados não apresentam preparo para lidar } \\
\text { com questões da administração financeira pessoal, } \\
\text { demonstrando maiores níveis de endividamento } \\
\text { comparado aos seus ascendentes familiares. Os } \\
\text { achados apontam a necessidade de se obter uma } \\
\text { educação financeira de qualidade ainda na infância } \\
\text { e na adolescência. }\end{array}$ & $\begin{array}{l}\text { Fernandes } \\
\text { e Candido } \\
(2014)\end{array}$ \\
\hline
\end{tabular}

\begin{tabular}{|l|}
\hline \multicolumn{1}{|c|}{ Objetivos } \\
\hline Identificar o nível de alfabetização \\
financeira de estudantes, de jovens \\
trabalhadores e de aposentados. O \\
estudo também busca compreender \\
o comportamento de investimento \\
de aposentados e de trabalhadores.
\end{tabular}

\section{Estudos internacionais}

\begin{tabular}{|c|c|}
\hline Resultados & Autores \\
\hline $\begin{array}{l}\text { O conhecimento financeiro dos indianos é baixo } \\
\text { comparado aos padrões internacionais. Os } \\
\text { comportamentos e as atitudes financeiras aparentam } \\
\text { ser positivos. O planejamento financeiro da } \\
\text { aposentadoria inicia ainda quando jovens e a maior } \\
\text { parte dos respondentes afirmam ter estimado suas } \\
\text { necessidades de renda pós-aposentadoria. }\end{array}$ & $\begin{array}{l}\text { Agarwalla } \\
\text { et al. } \\
(2012)\end{array}$ \\
\hline $\begin{array}{l}\text { Os recém-formados têm menos conhecimento } \\
\text { sobre questões financeiras diárias. Os estudantes } \\
\text { tiveram oportunidade de responder "não sei" } \\
\text { se assim desejassem. A maior parte dos recém- } \\
\text { formados admite não saber conceitos relacionados a } \\
\text { investimentos em renda variável. }\end{array}$ & $\begin{array}{l}\text { A n s o n g } \\
(2011)\end{array}$ \\
\hline $\begin{array}{l}\text { Os resultados do estudo piloto destacam a falta } \\
\text { de conhecimento financeiro entre uma proporção } \\
\text { considerável da população de cada país analisado. } \\
\text { Também foi identificado espaço para melhorias em } \\
\text { termos de comportamentos financeiros, enquanto as } \\
\text { atitudes financeiras variaram amplamente entre os } \\
\text { países. }\end{array}$ & $\begin{array}{l}\text { Atkinson } \\
\text { e Messy } \\
(2012)\end{array}$ \\
\hline $\begin{array}{l}\text { A alfabetização financeira na Suíça é alta } \\
\text { pelos padrões internacionais, sendo fortemente } \\
\text { correlacionada à poupança para aposentadoria. A } \\
\text { alfabetização financeira mais baixa é associada a } \\
\text { determinadas variáveis sociodemográficas. }\end{array}$ & $\begin{array}{l}\text { Brown e } \\
\text { Graf } \\
(2013)\end{array}$ \\
\hline $\begin{array}{l}\text { Estudantes universitários não têm conhecimento } \\
\text { de finanças pessoais. O baixo nível limitará sua } \\
\text { habilidade de tomar decisões informadas. }\end{array}$ & $\begin{array}{l}\text { Chen e } \\
\text { Volpe } \\
(1998)\end{array}$ \\
\hline
\end{tabular}

Determinar até que ponto os recém-formados do ensino médio entendem os conceitos financeiros básicos do consumidor e verificar os tópicos para os quais uma proporção significativa de estudantes admite não ter conhecimento.

Mensurar o nível de alfabetização financeira em 14 países de quatro continentes, por meio de instrumento desenvolvido pela Rede Internacional de Educação Financeira da OCDE.

Analisar o nível de alfabetização financeira na Suíça e examinar como a alfabetização financeira se relaciona com o planejamento de aposentadoria.

Investigar o nível de alfabetização financeira de estudantes universitários, a relação entre a alfabetização e as características dos estudantes e os impactos da alfabetização financeira nas suas opiniões e decisões. 


\begin{tabular}{|l|l|l|}
\hline $\begin{array}{l}\text { Desenvolver um construto padrão } \\
\text { de alfabetização financeira }\end{array}$ & $\begin{array}{l}\text { Outros fatores podem implicar problemas financeiros. } \\
\text { É importante diferenciar, claramente, a alfabetização } \\
\text { financeira da educação financeira. }\end{array}$ & $\begin{array}{l}\text { H u s t o n } \\
(2010)\end{array}$ \\
\hline $\begin{array}{l}\text { Conduzir uma meta-análise } \\
\text { sistemática da literatura para } \\
\text { avaliar a relação entre alfabetização } \\
\text { financeira, educação financeira e } \\
\text { comportamentos financeiros, }\end{array}$ & $\begin{array}{l}\text { As intervenções para melhorar a alfabetização } \\
\text { financeira explicam apenas 0,1\% da variação nos } \\
\text { comportamentos financeiros estudados. A educação } \\
\text { financeira estudada até o momento tem sérias } \\
\text { limitações que foram mascaradas pelos efeitos } \\
\text { aparentemente maiores em estudos correlacionais. }\end{array}$ & $\begin{array}{l}\text { Fetemeyer } \\
\text { Lynch e }\end{array}$ \\
\hline
\end{tabular}

Font ado pelos autores (2019).

O quadro anterior apresenta um rol exemplificativo de estudos que buscaram investigar a alfabetização financeira e as temáticas relacionadas, tanto no contexto nacional, quanto no internacional. Convém destacar que a insuficiência na alfabetização financeira não é uma característica exclusiva de economias subdesenvolvidas ou emergentes. Muitos países desenvolvidos também apresentam níveis inadequados de alfabetização financeira. Os citados estudos também apresentam associações entre os níveis de alfabetização financeira e as variáveis socioeconômicas e demográficas. Tais associações são sintetizadas no quadro 2.

Quadro 2- Variáveis socioeconômicas/demográficas e educação/alfabetização financeira

\begin{tabular}{|c|c|c|}
\hline Variáveis & $\begin{array}{l}\text { Relação com a educação/alfabetização } \\
\text { financeira }\end{array}$ & Autores \\
\hline \multirow[t]{2}{*}{ Renda } & $\begin{array}{l}\text { Quanto maior a renda, maior o nível de } \\
\text { educação/alfabetização financeira. }\end{array}$ & $\begin{array}{l}\text { Atkinson e Messy (2012); Brown e Graf } \\
\text { (2013); Chen e Volpe (1998); Delavande, } \\
\text { Rohwedder e Willis (2008); Lusardi (2015); } \\
\text { Michels (2015); Potrich, Vieira e Paraboni } \\
\text { (2013); Potrich, Vieira e Kirch (2014). }\end{array}$ \\
\hline & $\begin{array}{l}\text { A renda possui efeito positivo; porém, } \\
\text { pequeno, no grau de conhecimentos } \\
\text { financeiros. }\end{array}$ & Monticone (2010). \\
\hline \multirow{2}{*}{ Idade } & $\begin{array}{l}\text { Adultos com menos de } 30 \text { anos tendem a ser } \\
\text { menos educados financeiramente; }\end{array}$ & $\begin{array}{l}\text { Brown e Graf (2013); Chen e Volpe } \\
\text { (1998). }\end{array}$ \\
\hline & $\begin{array}{l}\text { Adultos de meia idade possuem os maiores } \\
\text { níveis de alfabetização financeira. }\end{array}$ & $\begin{array}{l}\text { Delavande, Rohwedder e Willis (2008); } \\
\text { Atkinson e Messy (2012). }\end{array}$ \\
\hline \multirow[t]{2}{*}{ Gênero } & $\begin{array}{l}\text { As mulheres, geralmente, apresentam } \\
\text { menores níveis de educação/alfabetização } \\
\text { do que os homens. }\end{array}$ & $\begin{array}{l}\text { Agarwalla et al. (2012); Atkinson e Messy } \\
\text { (2012); Chen e Volpe (1998); Brown e } \\
\text { Graf (2013); Delavande, Rohwedder e } \\
\text { Willis (2008); Michels (2015); Potrich, } \\
\text { Vieira e Paraboni (2013); Potrich; Vieira } \\
\text { e Kirch (2014); Scheresberg (2013). }\end{array}$ \\
\hline & $\begin{array}{l}\text { Homens são mais autoconfiantes em } \\
\text { questões financeiras e possuem maior } \\
\text { predisposição ao risco }\end{array}$ & Lucena e Marinho (2013). \\
\hline \multirow{2}{*}{ Estado civil } & $\begin{array}{l}\text { Solteiros possuem os maiores níveis de } \\
\text { educação financeira. }\end{array}$ & Potrich, Vieira e Kirch (2014). \\
\hline & $\begin{array}{l}\text { Casados possuem os maiores níveis de } \\
\text { alfabetização financeira. }\end{array}$ & $\begin{array}{l}\text { Agarwalla et al. (2012); Brown e Graf } \\
\text { (2013). }\end{array}$ \\
\hline
\end{tabular}




\begin{tabular}{|c|c|c|}
\hline \multirow[t]{2}{*}{ Escolaridade } & $\begin{array}{l}\text { Maior escolaridade está associada } \\
\text { aos maiores níveis de conhecimentos } \\
\text { financeiros. }\end{array}$ & $\begin{array}{l}\text { Agarwalla et al. (2012); Atkinson e Messy } \\
\text { (2012); Brown e Graf(2013); Chen e Volpe } \\
\text { (1998); Delavande, Rohwedder e Willis } \\
\text { (2008); Potrich, Vieira e Kirch (2014). }\end{array}$ \\
\hline & $\begin{array}{l}\text { Nível de formação influencia, de maneira } \\
\text { sutil, a educação financeira; }\end{array}$ & Scheresberg (2013). \\
\hline Ocupação & $\begin{array}{l}\text { Funcionários públicos possuem maior } \\
\text { propensão a possuir alto grau de } \\
\text { alfabetização financeira. }\end{array}$ & Potrich, Vieira e Kirch (2014). \\
\hline Dependentes & $\begin{array}{l}\text { Indivíduos, com os maiores níveis de educação } \\
\text { financeira, não possuem dependentes. }\end{array}$ & Potrich, Vieira e Kirch (2014). \\
\hline
\end{tabular}

Fonte: adaptado de Potrich, Vieira e Kirch (2014).

Tendo em vista os determinantes do quadro 2, neste estudo, buscou-se analisar o nível de alfabetização financeira dos militares, relacionando-se com a maioria das variáveis abordadas. Para tal investigação, descrevem-se, a seguir, os procedimentos metodológicos utilizados.

\section{METODOLOGIA}

Este estudo tem como objetivo estimar o nível de alfabetização financeira dos militares vinculados a uma Organização Militar da fronteira gaúcha. Para alcançar tal objetivo, adotou-se uma pesquisa de caráter descritivo e quantitativo, tendo como método o levantamento tipo Survey (HAIR et al., 2005; GIL, 2002).
A população-alvo correspondeu aos militares de uma Organização Militar situada no estado do Rio Grande do Sul. Com relação à amostra, optou-se por uma amostragem probabilística com estratificação proporcional (HAIR et al., 2005). Dessa forma, realizou-se a divisão da amostra em razão de seu nível hierárquico, que é a distinção usual no âmbito do Exército. Os elementos da amostra estratificada foram selecionados por meio de amostras aleatórias simples a partir dos estratos. Com base na equação de Barbetta (2002), para uma população de 174 militares, obteve-se uma amostra mínima de 64 respondentes (tabela 1), admitindo-se um erro amostral de $10 \%$, que corresponde ao percentual usualmente empregado em estudos de ciências sociais (SAMPIERI; COLLADO; LUCIO, 2013).

Tabela 1 - Cálculo amostral

\begin{tabular}{lll}
$\begin{array}{l}\text { Legenda: } \mathrm{N}=\text { Tamanho da população } \\
n=\text { Tamanho da amostra }\end{array}$ & $\begin{array}{l}=\text { Uma primeira aproximação para o tamanho da amostra } \\
=\end{array}$ \\
\hline $\boldsymbol{n}_{\mathbf{0}}=\frac{\mathbf{1}}{\boldsymbol{E}_{\mathbf{0}}^{\mathbf{2}}} \quad \boldsymbol{n}=\frac{\boldsymbol{N} \cdot \boldsymbol{n}_{\mathbf{0}}}{\boldsymbol{N}+\boldsymbol{n}_{\mathbf{0}}}$ & $n_{0}=\frac{1}{\mathbf{0 , 1 0 ^ { 2 }}}=\mathbf{1 0 0}$ & $\boldsymbol{n}=\frac{(\mathbf{1 7 4} \cdot \mathbf{1 0 0})}{(\mathbf{1 7 4 + 1 0 0})}=\mathbf{6 3}, \mathbf{5 0} \cong \mathbf{6 4}$
\end{tabular}

Fonte: elaborado pelos autores com base em Barbetta (2002).

Com o tamanho da amostra estabelecido, partiu-se para a demarcação do tamanho proporcional da amostra de cada estrato (Tabela 2).

Tabela 2 - Cálculo do tamanho da amostra por estrato

\begin{tabular}{l|c|c|c}
\hline \multicolumn{1}{c|}{ Posto/Graduação } & Proporção de elementos no estrato & Operação & Amostra por estrato \\
\hline Oficiais & $8,04 \%$ & $8,04 \%$ de 64 & 5 \\
\hline Subtenentes e Sargentos & $14,94 \%$ & $14,94 \%$ de 64 & 10 \\
\hline Cabos e soldados & $36,20 \%$ & $36,20 \%$ de 64 & 23 \\
\hline Efetivo Variável & $40,80 \%$ & $40,80 \%$ de 64 & 26 \\
\hline Total & $\mathbf{1 0 0} \%$ & - & $\mathbf{6 4}$ \\
\hline
\end{tabular}

Fonte: elaborado pelos autores com base em Hair et al. (2005). 
Conforme apresentado na tabela 2, o cálculo das amostras estratificadas empregou a proporção percentual de cada estrato da população. Destarte, a amostra total foi distribuída de acordo com a representatividade de cada nível hierárquico no total efetivo da OM.

Os dados utilizados, neste estudo, foram obtidos por meio da aplicação de questionários, que foram estruturados a partir de 50 questões objetivas e divididas em quatro blocos, construídos, conforme Potrich, Vieira e Kirch (2014). O bloco I teve por objetivo identificar as atitudes financeiras, e o bloco II mensurou os comportamentos financeiros. Essas seções contam com questões baseadas em escala $\mathrm{Li}$ kert, de cinco pontos. Na seção I, quanto mais o respondente discorda das afirmações, melhores serão suas atitudes financeiras. Já na Seção II, quanto maior a frequência em que o respondente afirma reproduzir os comportamentos descritos, melhor seu comportamento financeiro. $\mathrm{O}$ bloco III é composto por questões que visam determinar o conhecimento financeiro, em que os respondentes foram classificados de acordo com a pontuação obtida, sendo que, para cada acerto, foi computado um ponto.

Aqueles que obtiveram pontuação inferior a 8 foram classificados como detentores de baixo nível de conhecimento financeiro. Os que alcançaram escore entre 8 e 10 foram considerados como possuidores de nível intermediário. Por fim, os que atingiram pontuação superior a 10 foram considerados portadores de alto nível de conhecimento financeiro (CHEN; VOLPE, 1998; POTRICH; VIEIRA; KIRCH, 2014). Por fim, o bloco IV é composto por questões estruturadas e tem por finalidade traçar o perfil da amostra.

A aplicação do instrumento de coleta deu-se in loco, sendo os questionários entregues e recolhidos pessoalmente pelos pesquisadores. As informações coletadas tiveram tratamento estatístico por meio do software SPSS ${ }^{\circledR} 20.0$. Os dados foram analisados, em um primeiro momento, mediante estatística descritiva, com uso de medidas de tendência central e medida de dispersão. Posteriormente, na tentativa de explicar os fenômenos observados, foi verificada a existência de relação entre variáveis por meio do Teste $t$ e da análise de variância (ANOVA). A confiabilidade dos construtos não foi mensurada, uma vez que se utilizou de instrumento de coleta de dados já validado em estudo anterior (POTRICH; VIEIRA; KIRCH, 2014).

O modelo utilizado, denominado "termômetro de alfabetização financeira", teve sua eficiência comprovada por Potrich, Vieira e Kirch (2016). Tal metodologia de mensuração utiliza os resultados obtidos no âmbito dos construtos atitudes, conhecimentos e comportamentos financeiros como base para definição de dois conglomerados, sendo um com os indivíduos com baixo grau de alfabetização financeira e outro com os indivíduos bem alfabetizados financeiramente. $\mathrm{O}$ indicador utilizado pelos autores permite classificar qualquer indivíduo nesses dois grupos, com base na distância euclidiânia quadrática em relação ao centro de cada conglomerado. Portanto, cabe salientar que as medidas de confiabilidade dos dados obtidos obedecem ao apresentado naquele estudo.

A próxima seção descreve e discute os resultados encontrados a partir da pesquisa de campo realizada.

\section{RESULTADOS}

Nesta seção, são apresentados os resultados e as discussões provenientes dos dados coletados com os militares. A fim de responder à questão central desta pesquisa, foram estabelecidos três tópicos norteadores para o desenvolvimento da análise dos dados. O primeiro refere-se a traçar o perfil da amostra estudada; o segundo tópico tem por finalidade analisar o nível de alfabetização financeira dos militares, e, por fim, no terceiro tópico, busca-se identificar quis os fatores sociodemográficos e econômicos que influem na formação desses níveis no âmbito dos militares da organização analisada

\subsection{PERFIL DOS RESPONDENTES}

Depois da coleta de dados, foram obtidos 
106 questionários válidos, superando a amostra mínima definida. Viu-se que a maior parte dos servidores da Organização Militar são jovens de até 25 anos (70,8\%), pertencentes ao gênero masculino $(98,1 \%)$. Preponderam os solteiros $(70,8 \%)$ e a maioria dos respondentes não possuem dependentes $(76,4 \%)$. As variáveis apresentadas também demonstram que os respondentes, em sua maioria, não constituíram uma família com dependentes, o que lhes permite o uso individualizado de sua renda.

A variável escolaridade mostra maior dispersão na formação do perfil da amostra, porém predominam os respondentes de nível médio $(52,83 \%)$. Por outro lado, $16,98 \%$ dos respondentes estão cursando o nível superior, e 17,93\% já o concluíram ou possuem formação de pós-graduação. Pode-se considerar que o efetivo da organização possui escolaridade de intermediária a alta, que tende a aumentar a educação financeira do indivíduo (ATKINSON; MESSY, 2012; POTRICH; VIEIRA; KIRCH, 2014).

$\mathrm{Na}$ questão que avalia quem possui renda na residência do respondente, além dele próprio, nota-se a prevalência de militares que moram com seus pais $(51,89 \%)$. Já que a amostra é formada, majoritariamente, por respondentes que cumprem o serviço militar obrigatório $(42,45 \%)$, este pode ser considerado um resultado relacionado à independência econômica dos indivíduos.
Por fim, na questão que avalia a renda familiar mensal, encontra-se a maior dispersão de respostas, que pode ser atribuída aos distintos níveis hierárquicos. Prevalece a faixa de R $\$$ $2.800,01$ a $\mathrm{R} \$ 3.500,00$, que obteve $16,98 \%$ das respostas válidas. Após a caracterização do perfil, analisou-se o nível de alfabetização financeira dos jovens militares, que é o objetivo geral da pesquisa.

\subsection{NÍVEL DE ALFABETIZAÇÃO FI- NANCEIRA}

Para mensurar os conhecimentos financeiros, foi utilizada uma escala com base no número de acertos. O somatório de acertos, que varia de 0 a 13 pontos, foi dividido pelo número de questões para se obter um fator entre 0 e 1 (POTRICH; VIEIRA; PARABONI, 2013). Adaptando a escala de Chen e Volpe (1998) para o fator entre 0 e 1, a classificação alterou-se, ficando o baixo nível de conhecimentos financeiros para pontuação menor que 0,6153 ; nível intermediário para pontuação entre 0,6153 e 0,7692; e alto nível de conhecimentos financeiros para escores acima de 0,7692 (POTRICH; VIEIRA; KIRCH, 2014). A análise inicial do nível de conhecimentos financeiros se deu com base na estatística descritiva (tabela 03):

Tabela 3 - Estatística descritiva dos conhecimentos financeiros

\begin{tabular}{c|c|c|c|c|c|c}
\hline $\begin{array}{c}\text { Conhecimentos } \\
\text { Financeiros }\end{array}$ & Mínimo & Máximo & Média & Moda & Mediana & Desvio Padrão \\
\cline { 2 - 7 } & 0 & 1 & 0,60 & 0,69 & 0,61 & 0,22 \\
\hline
\end{tabular}

Fonte: dados da pesquisa (2019).

Pode-se afirmar que a média de conhecimentos financeiros dos militares da organização está no nível baixo, tendente ao nível intermediário. $\mathrm{O}$ baixo nível de conhecimento financeiro também foi evidenciado em pesquisas anteriores, como Matta (2007) e Oliveira (2012) no Brasil, Lusardi, Mitchel e Curto (2010) nos Estados Unidos, Ansong (2011) na África Ocidental, e Sekita (2011) no Japão. Tem-se assim, um resultado relevante, visto que o conhecimento financeiro é representativo da educação financeira do indivíduo, além de que constitui uma dimensão importante para a formação de atitudes e de comportamentos financeiros.

Na sequência, as questões referentes à atitude financeira foram mensuradas por meio de escala Likert de cinco pontos, em que a maior discordância das afirmações apresentadas se traduziria nas melhores atitudes finan- 
ceiras. As respostas desta seção do questionário foram aplicadas à fórmula matemática discriminada a seguir, conforme Potrich, Vieira e Kirch (2016):

$$
\frac{(0,26 * Q 2)+(0,49 * Q 9)+(0,25 * Q 10)}{5}
$$

Avaliando-se a estatística descritiva das atitudes financeiras, constata-se que os respondentes se encontram em um nível intermediário de atitudes financeiras, uma vez que esta escala possui sentido inverso:
A média dos comportamentos financeiros dos respondentes ficou em um nível intermediário, tendente a um nível superior se considerarmos a moda e a mediana. Tal resultado revela que, apesar de conhecimentos mais limitados, os militares possuem alguns hábitos financeiros adequados. Atkinson e Messy (2012) consideram os comportamentos financeiros como o componente mais importante da alfabetização financeira, pois conduzem a resultados positivos ou negativos na gestão financeira

Tabela 4 - Estatística descritiva das atitudes financeiras

\begin{tabular}{c|c|c|c|c|c|c}
\hline \multirow{2}{*}{ Atitudes financeiras } & Mínimo & Máximo & Média & Moda & Mediana & Desvio Padrão \\
\cline { 2 - 7 } & 0 & 1 & 0,32 & 0,41 & 0,30 & 0,11 \\
\hline
\end{tabular}

Fonte: dados da Pesquisa (2019).

As questões validadas para medir esse componente da alfabetização financeira concentravam-se em verificar se o respondente possuía preocupação com o seu futuro, ou se suas ações de gestão financeira são mais imediatistas. Com base nos resultados encontrados, conclui-se que os militares alocados à organização analisada reconhecem a importância de destacar o futuro na gestão financeira pessoal, mesmo que tenham evidenciado um baixo nível de conhecimento financeiro. De maneira geral, não demonstraram um comportamento imediatista, preocupando-se com as decisões financeiras futuras.

No tocante ao comportamento financeiro, a maior frequência de reprodução dos comportamentos apresentados significa melhores comportamentos financeiros. A equação utilizada para determinar esse componente é apresentada a seguir (POTRICH; VIEIRA; KIRCH, 2016): pessoal. De tal modo, pode-se considerar que parte do efetivo militar da organização analisada aproxima-se de um nível satisfatório de alfabetização financeira por reproduzirem comportamentos adequados.

Cabe ressaltar que as questões, utilizadas para mensurar os comportamentos financeiros (POTRICH; VIEIRA; KIRCH, 2016), indagavam sobre a frequência com que os respondentes fazem reservas com parte de sua renda. As respostas indicam que esse comportamento é reproduzido na organização, porém não é um hábito sistemático de todos os servidores. Quanto aos níveis de comportamentos financeiros, há uma dispersão de escores, ou seja, a homogeneidade de perfil sociodemográfico não se manifesta na homogeneidade de comportamentos financeiros. Apesar de a organização possuir um efetivo com determinadas características uniformes, as

$$
\frac{(0,22 * Q 13)+(0,23 * Q 20)+(0,19 * Q 28)+(0,15 * Q 31)+(0,21 * Q 36)}{5}
$$

A análise da estatística descritiva é sintetizada na tabela 5:

Tabela 5 - Estatística descritiva dos comportamentos financeiros

\begin{tabular}{c|c|c|c|c|c|c}
\hline $\begin{array}{c}\text { Comportamentos } \\
\text { financeiros }\end{array}$ & Mínimo & Máximo & Média & Moda & Mediana & Desvio Padrão \\
\cline { 2 - 7 } & 0,2 & 1 & 0,65 & 1 & 0,71 & 0,22 \\
\hline
\end{tabular}

Fonte: dados da pesquisa (2019). 
diferenças entre os comportamentos financeiros dos indivíduos são evidentes.

Uma vez mensurados os níveis dos componentes da alfabetização financeira e feita sua análise prévia de forma isolada, partiu-se para a classificação dos respondentes em alto e baixo nível de alfabetização financeira. Para tanto, os resultados foram inseridos nas equações abaixo discriminadas (POTRICH; VIEIRA; KIRCH, 2016):

$$
\begin{aligned}
& D_{0}=(0,49-\text { Atit })^{2}+(0,55-\text { Comp })^{2}+(0,57-\text { Conh })^{2} \\
& D_{1}=(0,37-\text { Atit })^{2}+(0,85-\text { Comp })^{2}+(0,82-\text { Conh })^{2}
\end{aligned}
$$

Onde: Atit $=$ Índice de Atitudes Financeiras; Comp = Índice de Comportamentos Fi- nanceiros; e Conh = Índice de Conhecimentos Financeiros.

Com base nas prescrições de Potrich, Vieira e Kirch (2016), partiu-se para a aplicação das equações, que resultou na classificação de 65 indivíduos no grupo de baixo nível de alfabetização financeira e de 41 respondentes como portadores de alto nível de alfabetização financeira. Como foi o verificado em estudos anteriores, de Potrich, Vieira e Kirch (2016) e Silva et al. (2017), a maior parte dos militares da organização analisada demonstrou níveis insatisfatórios de alfabetização financeira.

Tabela 6 - Estatística descritiva segundo a classificação de alfabetização financeira

\begin{tabular}{c|c|c|c|c|c|c|c|c}
\hline \multirow{2}{*}{ Construto } & \multicolumn{4}{|c|}{ Baixo nível (n=65; 61\%) } & \multicolumn{4}{c}{ Alto nível (n= 41; 39\%) } \\
\cline { 2 - 9 } & Média & Moda & Mediana & $\begin{array}{c}\text { Desvio } \\
\text { Padrão }\end{array}$ & Média & Moda & Mediana & $\begin{array}{c}\text { Desvio } \\
\text { Padrão }\end{array}$ \\
\hline $\begin{array}{c}\text { Atitude fi- } \\
\text { nanceira }\end{array}$ & 0,35 & 0,40 & 0,35 & 0,12 & 0,27 & 0,30 & 0,30 & 0,08 \\
\hline $\begin{array}{c}\text { Comporta- } \\
\text { mento finan- } \\
\text { ceiro }\end{array}$ & 0,52 & 0,46 & 0,48 & 0,18 & 0,85 & 1,00 & 0,86 & 0,10 \\
\hline $\begin{array}{c}\text { Conheci- } \\
\text { mento finan- } \\
\text { ceiro }\end{array}$ & 0,49 & 0,46 & 0,46 & 0,18 & 0,78 & 0,92 & 0,76 & 0,16 \\
\hline
\end{tabular}

Fonte: dados da pesquisa, adaptado de Potrich, Vieira e Kirsch (2016).

A tabela 6 possibilita visualizar as diferenças entre os grupos classificados com alto (baixo) nível de alfabetização financeira. No campo das atitudes, nota-se uma diferença menos representativa do que a dos outros dois construtos. As pequenas diferenças em relação aos dois grupos demonstram que as atitudes financeiras não são determinantes para a classificação da alfabetização financeira, já que ambos os grupos convergem no mesmo sentido ao responderem a esse construto (POTRICH; VIEIRA; KIRCH, 2016).

Com base nas questões que obtiveram o maior número de associações positivas, percebe-se um comportamento financeiro conservador e de aversão às dívidas. Em contraste, as afirmações que alcançaram as menores frequências de reprodução referem-se ao hábito de calcular o patrimônio, anualmente, à diversificação de investimentos e ao volume e à liquidez deles. Desta forma, os comportamentos positivos restringem-se a hábitos básicos, visto que comportamentos mais avançados não são reproduzidos pela maior parcela de respondentes.

Assim como verificado no campo dos comportamentos financeiros, os níveis de conhecimentos financeiros são contrastantes entre os dois grupos. A parcela de servidores da organização com alto nível de alfabetização financeira corresponde a doze acertos, de treze possíveis nas questões de múltipla escolha, demonstrando domínio sobre conceitos e produtos relacionados às finanças pessoais. Em contrapartida, o grupo de respondentes detentores de baixo nível de alfabetização financeira obteve média de acertos muito inferior.

Fica ratificada ainda a relação de interpendência entre os conhecimentos e os compor- 
tamentos financeiros (MARTIN, 2007). Lusardi (2015) aponta que a alfabetização financeira é o meio que possibilita que os indivíduos participem, plenamente, da vida econômica. Esta relação de interdependência pode explicar a grande diferença entre os índices dos dois grupos na organização analisada. A maior gama de conhecimentos dos indivíduos alfabetizados, financeiramente, pode estar contribuindo para que esses tenham uma postura mais ativa e segura, que, por sua vez, contribui para o incremento nos comportamentos positivos.

\subsection{FATORES RELACIONADOS AO NÍVEL DA ALFABETIZAÇÃO FI- NANCEIRA}

Além de mensurar o nível de alfabetização financeira, este estudo preocupou-se em compreender quais são os fatores sociodemográficos e econômicos que influem na formação destes níveis no âmbito dos militares da organização analisada. Para atingir este propósito, utilizou-se da análise de variância (ANOVA).

Conforme apresentado anteriormente, as atitudes financeiras pouco diferem entre os grupos de alto e de baixo nível de alfabetização financeira (POTRICH; VIEIRA; KIRCH, 2016). Devido a isso, a ANOVA resultou no não surgimento de diferenças entre os grupos, independente de qual variável era testada. Sen- do assim, os resultados relativos às atitudes serão omitidos dos dados apresentados a seguir.

A primeira variável dependente analisada foi a idade, em que os resultados indicaram que essa variável influencia o nível de conhecimentos financeiros. Corroborando Chen e Volpe (1998) e Brown e Graf (2013), constatou-se que os militares com idade inferior a 30 anos tendem a ser menos educados financeiramente. Por outro lado, os níveis de conhecimentos financeiros e de comportamentos financeiros foram contrastantes entre os adultos de meia idade, representados pelo intervalo de 36 a 40 anos. Delavande, Rohwedder e Willis (2008) e Atkinson e Messy (2012) afirmam que os maiores níveis de alfabetização financeira são encontrados em indivíduos com esta idade. Porém, os resultados da pesquisa não permitem que essa indicação seja assegurada.

Enquanto os comportamentos apresentam as médias mais inferiores do índice, os conhecimentos atingem o nível que classifica a faixa etária considerada (36 aos 40 anos) como detentora de alto nível de conhecimentos, segundo a classificação adaptada de Chen e Volpe (1998). No campo dos comportamentos, essas diferenças podem ter ocorrido ao acaso e não por causa da variável idade. Essa constatação encontra amparo na significância das diferenças entre as médias neste construto, conforme apresentado na tabela 7 , na qual se o valor de Sig. superior a 0,05 :

Tabela 7 - ANOVA dos índices de alfabetização financeira por idade

\begin{tabular}{l|l|c|c|c|c|c}
\hline \multicolumn{2}{l|}{} & $\begin{array}{c}\text { Soma dos } \\
\text { quadrados }\end{array}$ & Df & $\begin{array}{c}\text { Quadrados } \\
\text { médios }\end{array}$ & F & Sig. \\
\hline \multirow{4}{*}{ Comportamentos } & Entre grupos & 0,455 & 06 & 0,076 & 1,514 & $\mathbf{0 , 1 8 1}$ \\
\cline { 2 - 7 } & Dentre grupos & 4,962 & 99 & 0,050 & & \\
\cline { 2 - 7 } Conhecimento & Total & 5,417 & 105 & & & \\
\hline & Entre grupos & 1,342 & 06 & 0,224 & 5,912 & $\mathbf{0 , 0 0 0}$ \\
\cline { 2 - 8 } & Dentre grupos & 3,744 & 99 & 0,038 & & \\
\cline { 2 - 8 } & Total & 5,086 & 105 & & & \\
\hline
\end{tabular}

Legenda: Df = Degrees of Freedom (Graus de liberdade). Número de determinações independentes menos o número de parâmetros estatísticos a serem avaliados na população. $\mathbf{F}$ = Variância entre grupos / Variância dentre grupos. Razões F maiores indicam diferenças significativas entre os grupos. Sig = Significância estatística. Relação entre duas variáveis que é verdadeira e não se deve a eventos aleatórios $(\mathrm{Sig}<0,05)$

Fonte: dados da pesquisa (2019). 
Posteriormente, foi testada a influência do nível hierárquico na formação dos índices de alfabetização financeira, sendo ela, a variável que mostrou a influência mais significativa nestes níveis, conforme tabela que segue:
Com relação ao estado civil, verificou-se um desempenho ligeiramente superior dos respondentes que se declararam casados no campo dos comportamentos e dos conhecimentos financeiros. Essa constatação corrobora Aga-

Tabela 8 - ANOVA dos índices de alfabetização financeira por nível hierárquico

\begin{tabular}{|c|c|c|c|c|c|c|}
\hline & & \begin{tabular}{|c} 
Soma dos \\
quadrados
\end{tabular} & df & $\begin{array}{l}\text { Quadrados } \\
\text { médios }\end{array}$ & $\mathbf{F}$ & Sig. \\
\hline \multirow{3}{*}{ Comportamentos } & Entre grupos & 0,644 & 03 & 0,215 & 4,583 & 0,005 \\
\hline & Dentre grupos & 4,774 & 102 & 0,047 & & \\
\hline & Total & 5,417 & 105 & & & \\
\hline \multirow{3}{*}{ Conhecimento } & Entre grupos & 1,546 & 03 & 0,515 & 14,848 & 0,000 \\
\hline & Dentre grupos & 3,540 & 102 & 0,035 & & \\
\hline & Total & 5,086 & 105 & & & \\
\hline
\end{tabular}

Legenda: Df = Degrees of Freedom (Graus de liberdade). Número de determinações independentes menos o número de parâmetros estatísticos a serem avaliados na população. F = Variância entre grupos / Variância dentre grupos. Razões F maiores indicam diferenças significativas entre os grupos; Sig = Significância estatística. Relação entre duas variáveis que é verdadeira e não se deve a eventos aleatórios $(\mathrm{Sig}<0,05)$

Fonte: dados da pesquisa (2019).

Verificou-se que existe grande distância entre a média de conhecimentos e de comportamentos financeiros entre o nível hierárquico mais alto da organização (Oficiais) e o estrato mais baixo (Soldados EV). Existem diversos fatores que diferem estes dois estratos, como renda, escolaridade e idade, além de diferenças ocultas e não mensuradas, como as necessidades e desejos, as aspirações pessoais e a percepção sobre os hábitos de consumo. Entretanto, essa análise simplificada demonstra que os jovens ingressantes no mercado de consumo (Soldados EV) não dominam os conceitos necessários para a eficiente gestão financeira pessoal, confirmando os achados de Fernandes e Candido (2014).

Os maiores níveis de conhecimentos e de comportamentos financeiros dos níveis hierárquicos mais altos da organização (militares de carreira) vão ao encontro do que afirmam Potrich, Vieira e Kirch (2014), no sentido de que funcionários públicos possuem maior propensão a possuir alto grau de alfabetização financeira. A ANOVA atesta que as diferenças entre as médias dos grupos são, estatisticamente, significativas. rwalla et al. (2012) e Brown e Graf (2013). Convém destacar que o nível de alfabetização financeira associado ao estado civil alinhou-se com o resultado de pesquisas realizadas fora do país, contrariando os achados de Potrich, Vieira e Kirch (2014), que viram, nos solteiros, os maiores níveis de alfabetização financeira. Essa divergência pode ser decorrente de outras variáveis que, aliadas ao estado civil, determinaram o pior desempenho deste grupo na organização analisada. Destaca-se, ainda, que o número restrito de respondentes que se declararam separados se mostrou insuficiente para que qualquer consideração sobre este grupo tivesse alguma precisão.

Também se relacionaram os níveis de alfabetização financeira com o fato de o respondente possuir ou não dependentes. Nesse aspecto, os militares que declararam possuir dependentes mostraram as maiores médias de conhecimentos e de comportamentos financeiros, contrariando Potrich, Vieira e Kirch (2014). De forma empírica, é possível afirmar que os indivíduos que possuem dependentes são forçados a manter comportamentos financeiros adequados, já que suas ações influenciarão na qualidade de vida de seus familiares. 
Novamente, cabe associar esse resultado às demais variáveis sociodemográficas. Na maioria dos casos, os militares, que afirmaram possuir dependentes também são pertencentes aos mais altos níveis hierárquicos, possuem as idades mais avançadas, maior escolaridade e maior renda. Dessa maneira, há margem para ponderar o peso da posse ou não de dependentes na formação do nível de alfabetização financeira.

No que diz respeito à escolaridade, viu-se uma relação de proporção direta entre essa variável e os níveis de conhecimento e de comportamentos financeiros, tal e qual pesquisas anteriores (CHEN; VOLPE, 1998; AGARWALLA et al., 2012; ATKINSON; MESSY, 2012; BROWN; GRAF, 2013; POTRICH; VIEIRA; KIRCH, 2014). Ressalta-se que os achados desta pesquisa contradizem que a escolaridade influencia, de maneira sutil, a educação financeira (SCHERESBERG, 2013). Os valores de Sig. encontrados no campo dos conhecimentos e dos comportamentos financeiros são 1,648 e 4,673, respectivamente, ou seja, com base no nível de significância, é possível afirmar que a escolaridade não produz efeito significativo em ambos os campos.

Passando à análise do efeito da renda na alfabetização financeira, também foi constatada relação entre o efeito desta variável na formação do nível de alfabetização financeira, uma vez que os resultados encontram amparo na literatura (DELAVANDE; ROHWEDDER; WILLIS, 2008; ATKINSON; MESSY, 2012; BROWN; GRAF, 2013; POTRICH; VIEIRA; PARABONI, 2013; LUSARDI, 2015; MICHELS, 2015).

Constatou-se que as menores rendas estão associadas aos menores níveis de conhecimentos financeiros. Os respondentes que obtivem as menores médias de comportamento financeiro são também aqueles que têm as menores faixas de renda. Esse resultado serve para enfatizar que essa parcela da população está mais exposta às consequências do atraso com a educação financeira no país, uma vez que demonstraram possuir conhecimentos financeiros limitados, além de afirmarem não reproduzir comportamentos financeiros adequados. Diante disso, é reforçada a necessidade de priorizar aqueles com maior restrição orçamentária em programas de educação financeira. Os resultados da ANOVA dos índices de alfabetização financeira considerando a renda dos indivíduos podem ser verificados na tabela 9 :

Tabela 9 - ANOVA dos índices de alfabetização financeira por renda

\begin{tabular}{c|l|c|c|c|c|c}
\hline \multicolumn{2}{l|}{} & $\begin{array}{c}\text { Soma dos } \\
\text { quadrados }\end{array}$ & Df & $\begin{array}{c}\text { Quadrados } \\
\text { médios }\end{array}$ & F & Sig. \\
\hline \multirow{4}{*}{ Comportamentos } & $\begin{array}{l}\text { Entre } \\
\text { grupos }\end{array}$ & 0,978 & 10 & 0,098 & 2,092 & $\mathbf{0 , 0 3 2}$ \\
\cline { 2 - 7 } & $\begin{array}{l}\text { Dentre } \\
\text { grupos }\end{array}$ & 4,440 & 95 & 0,047 & & \\
\cline { 2 - 7 } Conhecimento & Total & 5,417 & 105 & & & \\
\hline & $\begin{array}{l}\text { Entre } \\
\text { grupos }\end{array}$ & 1,526 & 10 & 0,153 & 4,074 & $\mathbf{0 , 0 0 0}$ \\
\cline { 2 - 7 } & $\begin{array}{l}\text { Dentre } \\
\text { grupos }\end{array}$ & 3,559 & 95 & 0,037 & & \\
\cline { 2 - 8 } & Total & 5,086 & 105 & & & \\
\hline
\end{tabular}

Legenda: Df = Degrees of Freedom (Graus de liberdade). Número de determinações independentes menos o número de parâmetros estatísticos a serem avaliados na população. $\mathbf{F}$ = Variância entre grupos / Variância dentre grupos. Razões F maiores indicam diferenças significativas entre os grupos; Sig = Significância estatística. Relação entre duas variáveis que é verdadeira e não se deve a eventos aleatórios $(\mathrm{Sig}<0,05)$

Fonte: dados da pesquisa (2019). 
Por fim, buscou-se compreender se o núcleo familiar, economicamente, ativo exerce alguma influência nos níveis de alfabetização financeira. Neste aspecto, notou-se que os piores escores estão associados aos militares que residem com seus pais. De maneira empírica, conclui-se que esses militares não têm a incumbência de praticar comportamentos financeiros adequados, pois encontram, na família, uma fonte de resguardo caso passem dificuldades financeiras. Por isso, deixam de aprimorar seus conhecimentos sobre finanças pessoais, o que é determinante para a condição do nível de alfabetização financeira na organização analisada.

Com base nos resultados apresentados, conclui-se que as variáveis que determinam as diferenças entre os níveis de conhecimentos e de comportamentos financeiros são a idade, o estado civil, a posse ou não de dependentes, a escolaridade, a renda, o nível hierárquico e a constituição dos lares, no tocante a residentes economicamente ativos. O pequeno número de respondentes do sexo feminino impossibilitou que o gênero fosse apontado como fator de influência nos níveis de alfabetização financeira. Ademais, salienta-se que nem todas as variáveis apresentadas exerceram influência de igual intensidade, sendo que algumas destas diferenças podem ter ocorrido naturalmente ou ao acaso.

\section{CONSIDERAÇÕES FINAIS}

A pesquisa buscou evidenciar o grau de alfabetização financeira dos militares de uma Organização Militar da fronteira gaúcha. Essa pretensão partiu do pressuposto de que o serviço militar obrigatório se apresenta como uma porta de entrada ao mercado de trabalho e, consequentemente, à inclusão financeira. Como resultado, verificou-se que a maior parte do efetivo de servidores militares possui baixo nível de alfabetização financeira. Em relação aos construtos formadores desse índice, constatou-se que a dimensão das atitudes pouco influi na formação dos níveis de alfabetização financeira. Os resultados demonstraram que ambos os grupos tiveram pontuações semelhantes nesta escala. Em contraste, foi possível verificar a relação direta entre conhecimentos financeiros e comportamentos financeiros, demonstrando que os primeiros são a causa e também o meio para as alterações e aprimoramentos comportamentais.

Ressalta-se que uma parcela significativa de militares atingiu altos escores de alfabetização financeira se comparados aos demais servidores da organização e aos resultados de pesquisas realizadas anteriormente. Embora existam outras variáveis associadas à formação desse cenário, algumas dessas ocultas e não mensuráveis, a principal contribuição desta pesquisa relaciona-se à apresentação de informações positivas sobre uma parcela da população desconsiderada em estudos anteriores.

Por outro lado, os militares com nível hierárquico inferior demonstraram ter uma baixa alfabetização financeira, a qual pode ser resultado de aspectos como idade, renda, escolaridade e núcleo familiar. Quanto a esse último, pode-se inferir que esses militares que compõem a amostra podem não ter a incumbência de praticar comportamentos financeiros adequados, pois encontram, na família, uma fonte de resguardo caso passem por dificuldades financeiras.

Como contribuição prática, esta pesquisa propiciou um conjunto de informações acerca do tema, que podem ser de interesse de diferentes tipos de organizações, de gestores e pesquisadores ligados ao corte da população estudada. Visto que a percepção sobre o comportamento, a atitude e o conhecimento financeiro tende a influenciar diretamente no comportamento de compra desses indivíduos, sendo relevantes para o planejamento de políticas e programas relacionados à educação financeira.

A compreensão sobre a alfabetização e a educação financeira associadas a diferentes camadas da população poderão contribuir para o desenvolvimento de ações governamentais que prevejam a implantação de programas de alfabetização financeira à população em geral, como políticas de prevenção ao endividamento e a transtornos compulsivos de compra, o desen- 
volvimento de ações de educação financeira em ambientes educacionais, dentre outras. Especialmente, ressalta-se a importância de alavancar os conhecimentos financeiros para que seja possível incentivar comportamentos adequados no que tange a decisões financeiras pessoais.

Como contribuição teórica, tem-se a interconexão dos conceitos de educação/alfabetização financeira. Ao utilizar a metodologia elaborada por Potrich, Vieira e Kirch (2014), evidenciou-se que as restrições de conhecimento financeiro podem ocasionar baixos níveis de alfabetização financeira, particularmente, nos comportamentos financeiros pessoais. Assim, ratifica-se a metodologia desenvolvida pelos autores supracitados, como uma forma de medir a alfabetização financeira, considerando, conjuntamente, a educação financeira (conhecimento financeiro). Além disso, os resultados servem como comparativo teórico com outras amostras, as quais geralmente são representadas por um público jovem.

O estudo teve como limitação o tamanho da amostra e a restrição a apenas uma Organização Militar. Também não foi possível estimar o peso em que cada variável influencia o nível de alfabetização financeira, ficando como sugestão para estudos futuros. Sugere-se, ainda, o uso de métodos de análise que permitam a generalização e o estabelecimento de relações causais entre as variáveis estudadas.

\section{REFERÊNCIAS}

AGARWALLA, S. K. et al. A survey of financial literacy among students, young employees and the retired in India. Retrieved February, v. 26, p. 2013, 2012.

ANDERLONI, L.; VANDONE，D. Risk of overindebtedeness and behavioral factors. 2010. Disponível em: https://papers.ssrn.com/ sol3/papers.cfm?abstract_id $=1653513$. Acesso em: 23 fev. 2019.

ANSONG, A. Level of knowledge in personal finance by university freshmen business stu- dents. African Journal of Business Management, v. 5, n. 22, p. 8933-8940, 2011.

ATKINSON, A.; MESSY, F. A. Measuring financial literacy: Results of the OECD. [S.l.]: OECD Publishing, 2012.

ÁVIlA, P. A. S. C.; FERREIRA, M. C. O. Educação financeira: materialismo e o endividamento do servidor público de Caraguatatuba. In: CONGRESSO INTERNACIONAL DE ADMINISTRAÇÃO, 32., 2019, Ponta Grossa-PR. Anais [...].. Ponta Grossa-PR, 2019.

BANCO CENTRAL DO BRASIL - BACEN. Série Cidadania Financeira: Estudos sobre Educação, Proteção e Inclusão / Banco Central do Brasil. 2. ed. Brasília: Banco Central do Brasil, 2015.

BANCO CENTRAL DO BRASIL - BACEN. Caderno de Educação Financeira: Gestão de Finanças Pessoais. Brasília: BCB, 2013. Disponível em: https:/www.bcb.gov.br/pre/pef/port/ caderno_cidadania_financeira.pdf. Acesso em: 15 jan. 2019.

BARBETTA, P. A. Estatística aplicada às ciências sociais. Santa Catarina: Ed. UFSC, 2002.

BRASIL. Decreto ${ }^{\circ} 7.397$ de 22 de dezembro de 2010. Institui a Estratégia Nacional de Educação Financeira - ENEF, dispõe sobre a sua gestão e dá outras providências. Diário Oficial da União, Brasília, DF, 23 dez. 2010.

BROWN, M.; GRAF, R. Financial literacy and retirement planning in Switzerland. Scholar Commons, University of South Florida, v. 6, n. 2, 2013.

CARVALHO, L. A.; SCHOLZ, Robinson Henrique. "Se vê o básico do básico, quando a turma rende": cenário da educação financeira no cotidiano escolar. Revista Brasileira de Gestão e Inovação (Brazilian Journal of Ma- 
nagement \& Innovation), v. 6, n. 2, p. 102-125, 2018.

CHEN, H.; VOLPE, R. P. An analysis of personal financial literacy among college students. Financial services review, v. 7, n. 2, p. 107-128, 1998.

DELAVANDE, A.; ROHWEDDER, S.; WILLIS, R. J. Preparation for retirement, financial literacy and cognitive resources. Working Papers wp190, University of Michigan, Michigan Retirement Research Center, 2008.

DIETRICH, J.; BRAIDO, G. M. Planejamento Financeiro Pessoal para Aposentadoria: Um Estudo com Alunos dos Cursos de Especialização de uma Instituição de Ensino Superior. Sociedade, Contabilidade e Gestão, v. 11, n. 2, 2016.

FERNANDES, A. H. S.; CANDIDO, J. G. Educação financeira e nível do endividamento: relato de pesquisa entre os estudantes de uma instituição de ensino da cidade de São Pau1o. Revista Eletrônica Gestão e Serviços, v. 5 , n. 2, p. 894-913, 2014.

FERNANDES, D.; LYNCH JR, J. G.; NETEMEYER, R. G. Financial literacy, financial education, and downstream financial behaviors. Management Science, v. 60, n. 8, p. 1861-1883, 2014.

GIAMBIAGI, F.; VILLELA, A. A. Economia brasileira contemporânea. [S.l.]: Elsevier Brasil, 2011.

GIL, A. C. Como elaborar projetos de pesquisa. São Paulo: Atlas, 2002.

GONÇALVES, V. N.; PONCHIO, M. C. Quem Pensa no Futuro Poupa Mais? O Papel Mediador do Conhecimento Financeiro na Relação entre Orientação para o Futuro e Segurança Financeira Pessoal. Revista Brasileira de Marketing, v. 17, n. 4, p. 472-486, 2018.
HAIR, J. et al. Fundamentos de métodos de pesquisa em administração. Porto Alegre: Bookman Companhia Ed., 2005.

HUSTON, S. J. Measuring financial literacy. Journal of Consumer Affairs, v. 44, n. 2, p. 296-316, 2010.

KEMPSON, E. Framework for the development of financial literacy baseline surveys. OECD, n. 1, 2009.

KIM, K. T.; ANDERSON, S. G.; SEAY, M. C. Financial literacy and financial decisions of millennials in the United States. SSRN Electronic Journal, 2017.

LEAL, J. A. Serviço Militar Obrigatório: a alternativa adequada. Coleção Meira Mattos-Revista das Ciências Militares, Rio de Janeiro, n. 17, abr. 2008.

LUCENA, Wenner Glaucio Lopes; MARINHO, Reiniele Alves de Lima. Competências financeiras: uma análise das decisões financeiras dos discentes no tocante as finanças pessoais. In: SEMINÁRIOS EM ADMINISTRAÇÃO, 16., 2013, São Paulo. Anais [...]. São Paulo: SEMEAD, 2013.

LUSARDI, A. Financial literacy skills for the 21st century: Evidence from PISA. Journal of consumer affairs, v. 49, n. 3, p. 639-659, 2015.

LUSARDI, A.; MITCHELL, O. S.; CURTO, V. Financial literacy among the young. The Journal of Consumer Affairs, v. 44, n. 2, p. 358380, 2010.

MARTIN, M. A literature review on the effectiveness of financial education. SSRN Electronic Journal, 2007.

MATTA, R. C. B. Oferta e demanda de informação financeira pessoal: o Programa de Educação Financeira do Banco Central do Brasil e os universitários do Distrito Federal. 2007. 214 f. 
Dissertação (Mestrado em Ciência da Informação) - Universidade de Brasília, Brasília, 2007.

MICHELS, A. M. Proposta de indicador de educação financeira. 2015. 45 f. Trabalho de Conclusão de Curso (Especialização em Gestão Pública) - Universidade Federal do Rio Grande do Sul, Porto Alegre, 2015. Disponível em: http://www.lume.ufrgs.br/handle/10183/131508. Acesso em: 16 mar. 2019.

MONTICONE, C. How Much Does Wealth Matter in the Acquisition of Financial Literacy? The Journal of Consumer Affairs, v. 44, n. 2, 2010.

OLIVEIRA, S. F. de; SANTANA, Phillipe Martins. Financial education at workplace. Revista Pensamento Contemporâneo em Administração, v. 13, n. 1, p. 123-149, 2019.

OLIVEIRA, M. V. S. S. A Corrente do Bem da Educação Financeira: o cidadão está aprendendo o que o Banco Central está ensinando? In: ENCONTRO DA ANPAD, 131., 2012, Rio de Janeiro. Anais [...]. Rio de Janeiro, 2012.

ORGANISATION FOR ECONOMIC CO-OPERATION AND DEVELOPMENT (OECD, 2005). Improving financial literacy: analysis of issues and policies. 2005. Disponível em: http:// www.oecdilibrary.org/financeandinvestment/improvingfinancialliteracy_9789264012578-em. Acesso em: 10 jan. 2019.

ORGANISATION FOR ECONOMIC CO-OPERATION AND DEVELOPMENT (OECD, 2012). High-Level Principles on National Strategies for Financial Education. 2012. Disponível em: http://www.oecd.org/daf/ fin/financial-education/OECD-INFE-Principles-National-Strategies-Financial-Education. pdf. Acesso em: 23 fev. 2019.

ORGANISATION FOR ECONOMIC CO-OPERATION AND DEVELOPMENT (OECD, 2013). Financial literacy and inclusion: Results of OECD/INFE survey across countries and by gender. OECD, Paris, 2013. Disponível em: https://www.oecd.org/daf/fin/financial-education/TrustFund2013_OECD_INFE_Fin Lit_and_Incl_SurveyResults_by_Country_ and_Gender.pdf Acesso em: 23 fev. 2019.

POTRICH, A.; VIEIRA, K. M.; KIRCH, G. Determinantes da alfabetização financeira: proposição de um modelo e análise da influência das variáveis socioeconômicas e demográficas. In: ENCONTRO DAANPAD, 37., 2014, Rio de Janeiro. Anais [...]. Rio de Janeiro: ANPAD, 2014.

POTRICH, A. C. G.; VIEIRA, K. M.; KIRCH, G. Você é alfabetizado financeiramente? Descubra no termômetro de alfabetização financeira. Revista Base (Administração e Contabilidade) da UNISINOS, v. 13, n. 2, 2016.

POTRICH, A. C.; VIEIRA, K. M.; PARABONI, A. L. O que influencia a alfabetização financeira dos estudantes universitários. In: SEMEAD-SEMINÁRIOS EM ADMINISTRAÇÃO, 16., 2013, São Paulo. Anais [...]. São Paulo: FEA-USP, 2013.

SAMPIERI, R. H.; COLLADO, C. F.; LUCIO, P. B. Metodologia de pesquisa. [S.l.]: Penso, 2013.

SANTOS, J. O. D. Finanças pessoais para todas as idades: um guia prático. São Paulo: Atlas, 2014.

SCHERESBERG, C. B. Financial literacy and financial behavior among young adults: evidence and implications. Scholar Commons, v. 6, n. 2, 2013.

SEKITA, S. Financial literacy and retirement planning in Japan. Journal of Pension Economics and Finance, v. 10, n. 4, p. 637-656, 2011.

SILVA, O. G. et al. Alfabetização financeira versus educação financeira: um estudo do comportamento de variáveis socioeconômicas e demográficas. Revista de Gestão, Finanças e Contabilidade, v. 7, n. 3, p. 279-298, 2017. 